\title{
Ventricular Pacing in Children
}

\author{
ARTHUR B. SIMON, MACDONALD DICK II, AARON M. STERN, DOUGLAS M. \\ BEHRENDT, and HERBERT SLOAN \\ From the Sections of Pediatric Cardiology and Thoracic Surgery, C.S. Mott Children's Hospital, and the Division \\ of Cardiology and the Departments of Pediatrics, Surgery and Internal Medicine, University of Michigan Medical \\ Center, Ann Arbor, Michigan
}

SIMON, A.B., ET AL.: Ventricular pacing in children. Ventricular pacing was performed in forty-one children ranging from one day to twenty years of age (median age $=10$ ). Weight of the recipient at implant ranged from $2 \mathrm{~kg}$. to $86 \mathrm{~kg}$. Indications included presyncope, syncope, dyspnea on exertion, congestive heart failure, postoperative infra-Hisian heart block, and inadequate cardiac rate during pharmacotherapy. Four patients died during follow-up, but no deaths were attributable to pacemaker management. In contrast, $66 \%$ of the patients required more than one pacemaker related-operative procedure, and $43 \%$ of leads implanted failed by 48 hours. Indications for permanent cardiac pacing in this population at this time are symptomatic congenital AV block, symptomatic sinus node disease, and $A V$ block in the postoperative period. Technological developments which might reduce complications seen in this population and electrophysiologic techniques which may better define indications for pacing in children are also reviewed. (PACE, Vol. 5, November-December, 1982)

ventricular pacing, congenital AV block, sinus node disease, postoperative AV block

Permanent pacemaker implantation for the palliative treatment of atrioventricular block and sinus node disorders in children is an accepted treatment modality. It is the purpose of this report to review our experience with this technique in the pediatric population, to report our experience with epicardial lead longevity in children, and to compare it with lead performance reports in adults, to present our policy for pacemaker implantation in children, and to review recent advances particularly relevant to pacemaker management in children.

\section{Materials \& Methods}

The records of all patients under the age of twenty-one who required permanent ventricular pacing at the C.S. Mott Children's Hospital or the University Hospital of the University of Michigan Medical Center from January 1, 1962 through December 31, 1979 were reviewed. Data

Address for reprints: Macdonald Dick II, M.D., Section of Pediatric Cardiology, F1123, C.S. Molt Children's Hospital, University of Michigan Medical Center, 1405 E. Ann Street, Ann Arbor, MI 48109

Received October 1, 1981; revised November 11, 1981 and January 26, 1982; accepted January 29, 1982. were summarized on precoded forms for subsequent computer analysis using methods previously described. ${ }^{1,2}$ The clinical indication for pacing, the time course relative to prior cardiac operative procedures, the nature of the associated cardiac malformations, the frequency of all cardiovascular operative procedures, and the incidence of pulse generator and lead complications were analyzed.

During the eighteen years of this study advances in surgical technique and available devices, as well as evolving clinical criteria for pacemaker implant, undoubtedly influenced the clinical course of these patients.

Surgical techniques evolved during the period of the study; four cardiovascular surgeons performed the implantation and, therefore, considerable variability in the specific technique employed is to be expected. The patients were paced with either General Electric,* Medtronic, $\dagger$ Cordis, $\neq$ Cardiac Pacemaker,** or Coratomic* $\dagger$ pulse generators through General

\footnotetext{
*General Electric, New York, New York, U.S.A.

†Medtronic, Inc., Minneapolis, Minn., U.S.A.

$\ddagger$ Cordis Corp., Miami, Florida, U.S.A.

${ }^{* *}$ Cardiac Pacemaker, Inc., St. Paul, Minn., U.S.A.

*+Coratomic, Inc., Indiana, Pa., U.S.A.
} 
Electric, Medtronic, Cardiac Pacemaker, or Cordis leads.

For the determination of lead performance, the status of both active and redundant leads implanted after 1965 on which threshold data were available was tabulated and an actuarial curve calculated. Lead performance was calculated from the day of implant to the day of failure or end of the follow-up period, December 31, 1980. Failure was defined as a chronic threshold greater than 5 volts either due to lead fracture or high threshold ("exit block").

Since 1978 electrophysiologic study has been used to identify the site of block in patients with atrioventricular conduction disturbances, and to evaluate sinus node function in patients with the clinical manifestations of sick sinus syndrome.

\section{Results}

From 1962 through 1979 forty-one children between the ages of one day to twenty years (median age $=10$ years) received a permanent pacemaker at our institution. There were twenty-four females and seventeen males. The weight at implant ranged from $2 \mathrm{~kg}$. in a six-dayold boy to $86 \mathrm{~kg}$. in an eighteen-year-old man. Clinical indications for pacemaker implant at our institution were revised periodically during the study period. Cardiac symptoms such as presyncope, syncope, dyspnea on exertion, and congestive heart failure, as well as the association of other congenital heart defects, in the presence of inadequate impulse formation and/or impaired atrioventricular conduction, served as the major impetus for pacemaker implant in 39 of the 41 patients. The remaining two patients received pacemakers to preserve an adequate cardiac rate during anti-arrhythmic pharmacotherapy.

A summary of the clinical diagnoses is presented in Table I. Within the nonsurgical group,

Table I.

Clinical Diagnoses

I. Non-Surgical Group

A. Sinus node disease (symptomatic)

1. Sinus bradycardia

2. With ventricular arrhythmias 2

B. Atrioventricular block

1. Second degree type I

2. Complete atrioventricular block

3. Complete atrioventricular block with other cardiac defect Atrial septal defect 2 Patent ductus arteriosus L-transposition of the great arteries 1

4. Complete atrioventricular block, late TOTAL 1

II. Post-operative Group

A. Sinus node disease

1. Endocardial Cushion Defect 2

2. D-transposition of the great arteries 2

B. Complete Atrioventricular Block (symptomatic) 7

D-transposition of the great arteries 6

Ventricular septal defect 4

Atrial septal defect (secundum type) 1

Endocardial cushion defect 2

Single ventricle 1

Ebstein's anomaly $\quad 1$

Aortic valve replacement (traumatic aortic rupture)

$\begin{array}{ll}\text { Tricuspid atresia } & 1\end{array}$

$\begin{array}{ll}\text { TOTAL } & 28\end{array}$ 
three patients had symptomatic sinus bradycardia, two associated with ventricular arrhythmias. Ten patients exhibited disturbances in atrioventricular conduction, five associated with congenital heart defects. The age at implant in the non-surgical group was bimodal with seven children under three years of age and six over eleven years of age at initial implant.

Twenty-four of the twenty-eight patients in the surgical group required pacing for complete atrioventricular block acquired at operation; four patients required pacemaker support for symptomatic surgically related sinus node disease, either because of bradycardia or for suppressive pharmacotherapy of tachyarrhythmias. Twenty-five of the patients have received their initial implant since 1971 whereas the other 16 were initially paced prior to 1971 . Although eighteen of twenty-eight post surgical patients (seventeen with AV block and one with sinus node dysfunction) received their pacemakers within one year of the repair of their structural heart disease, ten of these within thirty days, the remaining ten (seven with AV block and three with sinus node dysfunction) did not require pacing until much later, five not until eleven or more years after operation.
Among the ten patients who developed complete heart block following operation but were not immediately paced, nine did not become sufficiently symptomatic to warrant pacing until one month to five years following operation. The other patient developed transient atrioventricular block which resolved within two weeks only to return ten years later.

Two patients in whom complete atrioventricular block developed following surgery but were not immediately paced, demonstrated supra-Hisian block (within the atrioventricular node) at electrophysiologic study, and required pacemaker placement because of symptoms (syncope in one, and dyspnea on exertion with a fixed heart rate in the other). Two additional patients have surgical heart block and have not been paced-one is asymptomatic and has supra-Hisian block on electrophysiologic study, and a second is well but refused study and pacemaker implantation.

\section{Operative Procedures}

The major and minor cardiac and pacemaker related surgical procedures performed in this group of patients are tabulated in Table II. Twenty-five of the forty-one patients required

Table II.

Frequency of operative procedures required for both intracardiac repair and pacemaker related indications during the study interval 1962-1979. Pacemaker and cardiac procedures were not necessarily separate. The totals are derived by determining the product of numbers of patients who required the specified number of procedures.

\begin{tabular}{cccc}
$\begin{array}{c}\text { Number of } \\
\text { Patients }\end{array}$ & $\begin{array}{c}\text { Number of } \\
\text { Thoracotomies } \\
\text { Pertormed }\end{array}$ & $\begin{array}{c}\text { Number of } \\
\text { Pacemaker } \\
\text { Procedures } \\
\text { (Pulse Generator } \\
\text { Replacements } \\
\text { and Implants) }\end{array}$ & $\begin{array}{c}\text { Total Cardiac } \\
\text { and Pacemaker } \\
\text { Procedures }\end{array}$ \\
\hline 1 & 15 & 16 & 4 \\
2 & 6 & 11 & 15 \\
3 & 6 & 4 & 3 \\
4 & 6 & 2 & 7 \\
5 & 1 & 1 & 5 \\
6 & 1 & $3^{* *}$ & $3^{*}$ \\
TOTAL & 80 & 85 & 119 \\
\hline
\end{tabular}

* One required 6 , one required 7 and a third 10.

** Two required 6, one required 10. 
more than one pacemaker-related operative procedure; six required four or more. Eighty thoracotomies have been performed among these forty-one patients either for surgical repair of the congenital heart defect or for cardiac pacing. When both pacing and cardiac procedures are combined, half the patients have been operated upon three or more times.

\section{Implantation Techniques \& Complications}

The epicardial lead placement approach was used as the initial mode of pacing in thirty-eight of the forty-one patients, and the transvenous approach was used initially in three. One patient was converted to transvenous pacing after multiple lead failures with the epicardial technique. The manufacturer and lead models utilized, and the frequency and mode of lead failure are tabulated in Table III. Epicardial leads were implanted in the left ventricle through a lateral or anterolateral thoracotomy. Although thresholds were measured with different devices during the study interval, acute thresholds were accepted if less than $1 \mathrm{mV}$. Twenty of the 74 leads utilized were of the "sutureless" type and the remainder were myocardial plunge electrodes from four different manufacturers. The most commonly used lead, the Medtronic Model 5913, has undergone seven manufacturing modifications from 1972 to 1979 without model disignation change.*

During the study period the frequency of myocardial lead failure has been high (Table III). Longevity data are available on fifty-eight myocardial leads from four different manufacturers placed in thirty-five patients since 1965. Actuarial analysis reveals that only $75 \%$ of the leads were functioning 12 months after implant, $68 \%$ at 24 months after implant, and only $57 \%$ at 48 months after implant (Fig. 1). Thereafter only one additional myocardial lead has failed during the follow-up interval. Ten of the sixteen high threshold lead failures occurred in three patients. There was no significant lead failure difference since that date.

Our experience with transvenous pacing has involved only four patients. Two adolescents received transvenous right ventricular endocardial pacing systems ten years after cardiac repair (Tetralogy of Fallot in one, and atrial septal defect, secundum in the other) and are well two years later. The third patient is remarkable for duration of the lead system. She received her initial epicardial pacemaker in 1962 at age five because of symptomatic complete heart block following ventricular septal defect repair. She was converted in 1965 to a transvenous pacing

*Medtronic Corporation-Personal communication.

Table III.

Epicardial lead performance in 35 of the 41 patients over the follow-up period after 1964. Five transvenous leads which have all functioned normally for $<1$ to $>16$ years are not included.

\begin{tabular}{lcccccc}
\hline & \multicolumn{5}{c}{ Status } \\
\cline { 3 - 6 } Manufacturer & $\begin{array}{c}\text { Model } \\
\text { Number }\end{array}$ & Fracture & $\begin{array}{c}\text { High } \\
\text { Threshold }\end{array}$ & $\begin{array}{c}\text { Normal } \\
\text { Function }\end{array}$ & Inactive & Total \\
\hline Medtronic & 5815 & 2 & 12 & 21 & 5 & 40 \\
Medtronic & 6917 & - & 2 & 5 & 3 & 10 \\
Medtronic & $6917 \mathrm{~A}$ & - & - & 6 & 4 & 10 \\
Medtronic & 6913 & - & 2 & - & - & 2 \\
Cordis & $323-443$ & 2 & - & 2 & - & 4 \\
Coratomic & L-30 & - & - & 2 & 2 & 4 \\
CPI & 4913 & - & - & 2 & - & 2 \\
\multicolumn{1}{c}{ TOTAL } & & 4 & 16 & 38 & 14 & 72 \\
\hline
\end{tabular}




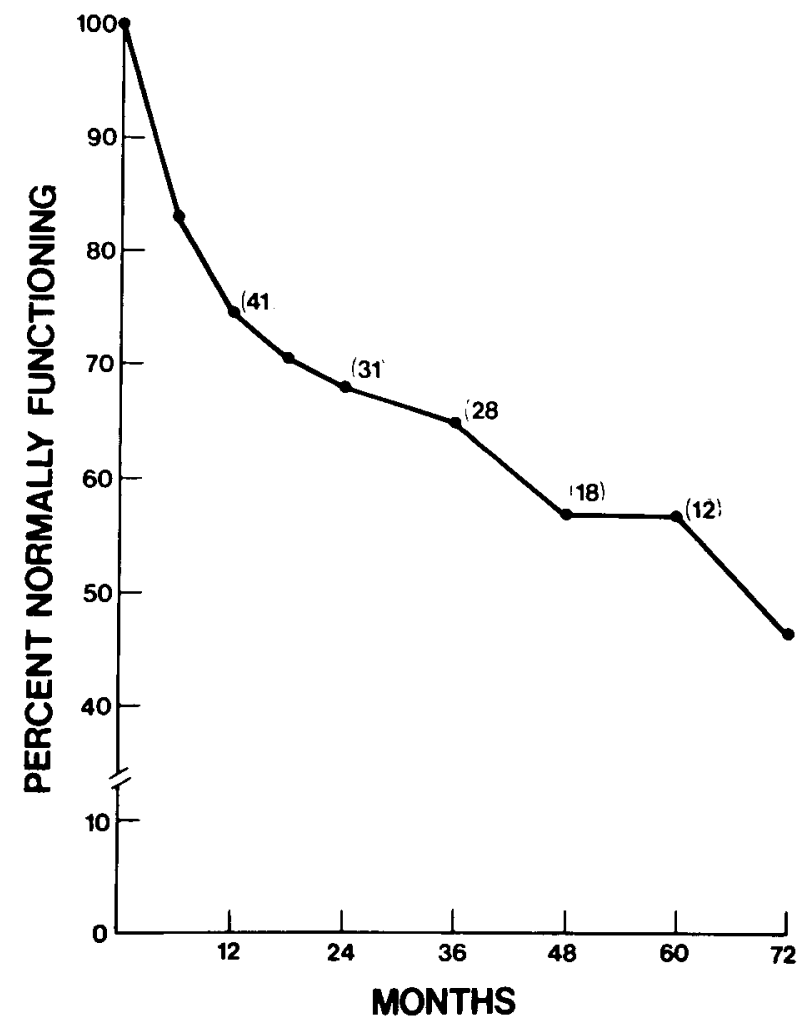

Figure 1. Percent of normally functioning myocardial leads related to time (months) computed by actuarial analysis. Numbers in parenthesis indicate the number of leads at risk at each interval.

system after failure of multiple epicardial leads. She has been continually paced from one transvenous electrode with an acceptable (less than 5 volts) threshold since. One patient with a transvenous lead expired within the first year following implant of noncardiac causes.

Pacemaker wound infection was noted in three patients. In each instance more than one surgical procedure was required to remove the old and re-implant a new pacing system.

\section{Clinical Course Following Implant}

Permanent pacing has been discontinued in three patients since initial implant. One, a nineteen-year-old girl underwent repair of Tetralogy of Fallot in 1963, followed by complete heart block. Repeated failure of epicardial implants led to patient refusal of further implant. She re- mains asymptomatic and unpaced. The second was a two-and-a-half month old infant with ventricular tachycardia alternating with sinus rhythm and transient 2:1 block. Pacing failure developed soon after implant and high thresholds (greater than 5 volts) were measured eighteen months later when the generator was removed. She has been in normal sinus rhythm with a right bundle branch block and first degree AV block since that time. Quinidine has controlled her ventricular arrhythmia. The third patient developed complete atrioventricular block following Mustard procedure at ten months of age for transposition of the great arteries. A pacemaker was implanted ten days following operation, but pacing ceased six months later because of lead failure. Normal sinus rhythm had reappeared and has persisted for five years. Two additional children have had resolution of their postoperative atrioventricular block with appropriate inhibition of their demand pacemakers; the opportunity to discontinue the pacing system has not yet arisen.

\section{Mortality}

There have been four deaths $(10 \%)$ in the series, none attributable to pacemaker malfunction. A fourteen-year-old boy with single ventricle, transposition of the great arteries, and pulmonary stenosis, had a pacemaker implanted 16 days after ventricular septation and a pulmonary valve replacement. He died suddenly thirty-nine months later. Ten days before his death his pacemaker had been functioning normally, but severe pulmonary artery hypertension and congestive heart failure were persistent prior to death. The second death was in a nineteen-year-old girl with Kearns syndrome, ${ }^{3}$ who died four months after pacemaker implantation due to bronchopneumonia and pancreatitis. The third was a three-year-old infant with ventricular septal defect, corrected transposition, atrial septal defect, and congenital atrioventricular block who had a permanent pacemaker implanted at the time of a BlalockTaussig anastomosis. She died of pneumonia four months later. The fourth death occurred in a seventeen-year-old boy with Down's syndrome, ventricular septal defect (endocardial 
cushion type), pulmonary artery hypertension, and mitral valve replacement. Intermittent complete heart block required a pacemaker implant to assure adequate heart rate shortly after operation. Recurrent diptheroid sepsis and ventricular arrhythmias, controlled by quinidine, complicated the 20-month postoperative course. At the time of his death, atrioventricular conduction was intact and the pacemaker was functioning normally in the demand mode at an escape rate of 40 beats per minute. The remaining 37 patients are alive and fully engaged in ageappropriate activities except for vigorous competive sports.

\section{Discussion}

Previous reviews of the status of pediatric patients requiring ventricular pacing have emphasized the specific etiology of the rhythm disturbances, ${ }^{4-9}$ technical aspects of the agespecific implantation problems of children, ${ }^{8,9}$ the natural history of arrhythmias which require pacing, ${ }^{10-16}$ as well as the long-term experience in pediatric patients who have received permanent pacemakers. ${ }^{17-19}$ Our data underscore the high morbidity but low mortality and often lifesaving intervention that accrues to children following ventricular pacing. Thirty-four children required ventricular pacing because of atrioventricular block, twenty-four surgically induced. Three of the four patients with post-surgical sinus node disease became symptomatic greater than three years after the operation and greater than ten years in two, suggesting that this abnormality may become more prevalent as this group of patients survives into adulthood. The bimodal distribution of age at initial implant, especially in those patients with congenital complete heart block, suggest that intrinsic escape rates that result in symptoms are either present very early in life or do not emerge until adolescence or young adult life..$^{19}$

The interval from cardiac repair to pacemaker implant in the surgical group may be related to the site of block. In contrast to the experience of others, ${ }^{5}$ seven of our patients who developed surgical complete heart block did not require pacing until late (greater than one year) in the follow-up period; two of these patients have undergone electrophysiologic study and both demonstrated supra-Hisian complete heartblock.

The epicardial lead approach using a variety of lead systems has not been entirely satisfactory. The survival of epicardial leads in this series is similar to that reported for other paced children during a comparable interval, ${ }^{14,17}$ but far worse than the epicardial experience reported for adults. Magilligan et al..$^{20}$ reported lead failure in 8 of 100 adults with both sutured and sutureless (Medtronic models 5913, 6913 and 6917) electrodes after 30-64 months. Edwards and Davies ${ }^{21}$ reported $13 \%$ epicardial lead failure rate at 30 months (Medtronic models 6913, 6914 and 6917). Mansour et al. ${ }^{22}$ experienced only four lead failures in 300 patients using the Medtronic 6917 sutureless electrode. Using the same lead Lawrie et al. ${ }^{23}$ reported only a $3.9 \%$ failure rate at 39 months on initial implants, but a $25 \%$ failure rate on patients referred for repeated procedures. Interestingly, two patients in their series had failure of both leads. In their well documented series, lead failure, consisting of high thresholds in all, occurred in $7.2 \%$ of 400 leads by 39 months.

For incompletely understood reasons, ten patients in our series developed high thresholds with multiple implants. Excluding the three patients paced prior to 1965 , when the lead fracture rate was higher and not representative of current experience, two patients have required two, and one patient three, thoracotomies within the first year of pacing for lead failure due to thresholds exceeding the five volt output of standard pulse generators available at the time. While one patient could be converted to a high output (10 volt) pulse generator, under local anesthesia, the remaining patients required repeat thoracotomy for new lead implantation. It is possible that this frequency of lead replacement in the future might not be as high now that multiprogrammable pulse generators whose output and pulse duration can be raised noninvasively after implantation are available. Obviously this benefit of technology would be helpful only for those patients who developed only a modest increase in threshold, and not to those with lead failure due to lead fracture or extremely high thresholds. 
Possible factors which may contribute to poor myocardial lead performance in children involve surgical technique as well as available technology.

Early myocardial electrodes required small stab wounds into the myocardium for insertion, followed by securing of the electrode to the myocardium with sutures. This method may result in hemorrhage, necrosis, and fibrosis at the site of placement. A rapid decrease in current density at the electrode-myocardial interface leading to failure of myocardial capture and subsequent system revision was not infrequently the result. ${ }^{14}$ Similar techniques are used in adults, and this explanation alone cannot explain the higher frequency of threshold rises in children seen in this series. Changes in electrode design, particularly the sutureless electrode, have simplified insertion and may be less traumatic to the myocardium, although data to support this conclusion are not available. Placement of the lead through the diaphragm to the generator pocket in the abdominal wall, rather than immediately beneath the ribs, removes a fulcrum on which the lead may wear and may reduce lead fracture. Creation of the abdominal generator pocket immediately pre-peritoneal, beneath the muscle layers of the abdominal wall rather than subcutaneously, has facilitated wound closure, especially in infants and small children, and probably has reduced the incidence of wound dehiscence and generator pocket infection. ${ }^{9}$ This technique has been facilitated by miniaturization of the pulse generators, achieved primarily by the application of micro-circuitry, and smaller but longer lasting power sources. A number of additional developments during the study interval have improved the long-term outlook for the paced child. The development of double or triple helicoil lead wires has apparently lengthened the life span of an implanted lead. The development of a simple pacemaker analysis system assists the surgeon in determination of the causes of pacing system malfunction and more accurately tests threshold of stimulation at the time of initial lead placement.

As suggested by our own limited experience, as well as that of others, ${ }^{24,25}$ there appears to be a role for transvenous patients in this age group. Repeated electrode repositioning which might be required with late displacement due to truncal growth in children would certainly appear to be preferable to the multiple thoracotomies required for epicardial lead placement. Percutaneous insertion of permanent leads now obviates the problem of venous access unavailability in this age group. ${ }^{24}$ Certainly, patients without right-to-left shunts who are over ten years of age, and perhaps younger, would be acceptable candidates for transvenous pacing. New positive fixation electrodes have substantially reduced the complication rates of transvenous approaches in adults and may hold promise in growing children. Furman and Young ${ }^{25}$ reported no excess lead difficulties using the transvenous technique in 12 of 13 pediatric patients paced transvenously-only one required conversion to epicardial leads because of repetitive displacement.

Based on this experience and that of others, ${ }^{12}$ the following is our current approach in the management of disturbances in impulse formation and conduction in children. The initial management relates to etiology. Patients with congenital complete heart block are paced upon the appearance of presyncope, syncope, congestive heart failure, or other rate related symptoms. Patients with sinus node disorders, either congenital, acquired, or surgically induced, receive a pacemaker upon the appearance of symptoms or to insure adequate impulse formation during pharmocotherapy for symptomatic tachyarrhythmias. Both groups of patients undergo electrophysiologic study prior to implant to identify the intrinsic escape mechanism, to localize the site of block, if present, and to assess intrinsic pacemaker response to rapid atrial pacing, atropine, isoproterenol infusion, and exercise. Permanent pacing for bradycardia alone in the isolated congenital AV block group has not been employed, despite an apparent higher risk of progression to a symptomatic course in this subgroup. ${ }^{28}$

Surgically induced rhythm disturbances are analyzed for time of onset, severity, adequacy of escape rhythm, response to exercise, and site of block (if present). Transient (less than three weeks following surgery] but stable impulse formation and conduction disturbances are managed in the immediate postoperative peri- 
od with temporary transthoracic epicardial wires (atrial or ventricular, depending upon the site of abnormality) and, prior to discharge, by ambulatory monitoring to insure adequate impulse formation and propagation. If complete atrioventricular block persists beyond three weeks, electrophysiologic study is recommended to identify the site of block; if surgical heart block is intra-Hisian or below the His, a permanent pacemaker is implanted. If the block is supra-Hisian, the patient asymptomatic, and the intrinsic pacemaker escape satisfactory by Holter monitoring, the parents are advised of both our experience and the reported experience of surgical heart block. ${ }^{5,12}$ Early in our experience (prior to the era of electrophysiologic study) pacemakers were withheld unless symptoms dictated their insertion. At present we recommend implant in the supra-Hisian group even in the absence of symptoms; despite this recommendation, the families of two children have refused implant; both children are well five and ten years after surgery. This experience, though small, suggests that supra-Hisian heart block in the absence of symptoms, with an adequate escape rate, may be less lifethreatening than infra-Hisian, or undifferentiated surgical heart block, a finding shared by Driscoll et al. ${ }^{12}$ Lesser degrees of conduction abnormalities such as bifascicular block or trifascicular disease, are followed closely by electrophysiologic studies at times of postoperative catheterization and by periodic ambulatory monitoring. This approach is designed to identify high-risk patients in need of pacemaker support without submitting all individuals with impulse formation and conduction abnormalities to long-term pacemaker management with its attendant high cost and morbidity.

Although we have utilized isotopic pulse generators in six patients in this series, we no longer

\section{References}

1. Simon, A.B. and Zloto, A.E.: Atrioventricular block: Natural history after ventricular pacing. Am. J. Cardiol., 41:500, 1979.

2. Simon, A.B. and Zloto, A.E.: Symptomatic sinus node disease: Natural history after permanent ventricular pacing. PACE, 2:305, 1979.

3. Roberts, N.K., Perloff, J.K., and Kark, R.A.P.: implant this type of unit. The pulse generators are more expensive than programmable lithium powered pulse generators; their major advantage, a long-life power source, is offset by the fact that the major complication of the pacing system in this age group in this series, which was almost exclusively with epicardial leads, is related to the development of high lead thresholds, not to the limited life span of the power source. Expected advances in lead systems and anticipated benefits from dual chamber pacing and flexibility obtained with pulse generator programmability is lost by reliance on this type of unit. Furthermore, although we know of no data indicating that nuclear-powered units constitute a health danger to the patient, the chronic (decades) use of this device in children may have risks unidentified at the present time. Finally, the reduction in random electronic malfunction and premature battery depletion as a result of advances in pulse generator circuitry design and manufacture, as well as the availability of telephone monitoring for early pacing system malfunction detection, have all simplified routine follow-up of the pacemaker patient. In summary, the childhood population requiring permanent pacing consists of patients with congenital and surgically induced abnormalities of impulse formation and conduction. The decision to implant a permanent pacemaker in this age group should be made with an appreciation of the rate of associated morbidity unique to children and the current state of pacing technology. Today, utilizing historical, noninvasive, and electrophysiologic data, one can develop a rational basis for the institution of pacing in children. Improvements in diagnosis of rhythm disturbances in children, as well as present and future technical advances in pacing system design, render this therapeutic technique applicable to all age groups. ${ }^{27}$

Cardiac conduction in the Kearns-Sayre syndrome (A neuromuscular disorder associated with progressive external ophthalmopelegia and pigmentary retinopathy). Am. J. Cardiol., 44:1396, 1979.

4. Isaacson, R., Titus, J.D., Merideth J., et al.: Apparent interruption of atrial conduction path- 
ways after surgical repair of transposition of great arteries. Am. J. Cardiol., 30:533, 1972.

5. El Said, G., Rosenberg, H., Mullins, C.E., et al.: Dysrhythmias after Mustard's operation for transposition of the great arteries. Am. J. Cardiol., 30:527, 1972.

6. Hofshire, P.J., Nicoloff, D.M., and Moller, J.H.: Postoperative complete heart block in 64 children treated with and without cardiac pacing. Am. J. Cardiol., 39:559, 1977.

7. Sondheimer, H.M., Izukawa, T., Olley, P.M., et al.: Conduction disturbances after total correction of Tetralogy of Fallot. Am. Heart J., 92:278, 1974.

8. Salama, F.: A suggested site for the implantation of myocardial pacemakers in infants and young children. Thorax, 31:346, 1976.

9. Amato J.J., Payne, D.D., Rheinlander, H.F., et al.: Intermuscular abdominal implantation of permanent pacemakers in infants and children. Ann. Thorac. Surg., 25:243, 1978.

10. Pahlajani, D.B., Serratto, M., Mehta, A., et al.: Surgical bifascicular block. Circulation, 52:82, 1975.

11. Yabek, S.M. and Jarmakani, J.M.: Sinus node dysfunction in children, adolescents, and young adults. Pediatrics, 61:593, 1978.

12. Driscoll, D.J., Gillette, P.C., Hallman, G.L., et al.: Management of surgical complete atrioventricular block in children. Am. J. Cardiol., 43:1175, 1979.

13. Young, D., Eisenberg, R., Fish, B., et al.: Wenckebach atrioventricular block (Mobitz Type I) in children and adolescents. Am. J. Cardiol., 40:393, 1977.

14. Gamble, W.J. and Owens, J.P.: Pacemaker therapy for conduction defects in the pediatric population. In H. Gelband, N.K. Roberts, (Eds.). Cardiac Arrhythmias in the Neonate Infant and Child, Appleton-Century Crofts, N.Y., 1977, pp. 461-525.

15. Greenwood, R.D., Rosenthal, A., Sloss, L.J., et al.: Sick sinus syndrome after surgery for congenital heart disease. Circulation, 52:208, 1975.
16. Neiderhauser, H., Simonin, P. and Friede, B.: Sinus function and conduction after repair of tetralogy of fallot. Circulation, 52:214, 1975.

17. Williams, W.G., Izukawa, T., Olley, P.M., et al.: Permanent pacing in infants and children, PACE, 1:439, 1978.

18. Shearin, R.P.N. and Fleming, W.H.: Fourteen years of implanted pacemakers in children. Ann. Thorac. Surg., 25:144, 1978.

19. Michaelsson, J. and Engle, M.A.: Congenital complete heart block: An international study of the natural history. Cardiovasc. Clin., 4:85, 1973.

20. Magellegan, D.J., Hakimi, M. and Davila, J.G.: The sutureless electrode: Comparison with transvenous and sutured epicardial electrode placement for permanent pacing. Ann. Thorac. Surg., 22:80, 1976.

21. Edwards, A.M. and Davies, J.G.: Analysis of the longevity of pacing electrodes. In Y. Watanabe (Ed.): Cardiac Pacing, Excerpta Medica, Amsterdam, 1977, pp. 539-542.

22. Mansour, K.A., Miller, J.I., Symbas, P.N., et al.: Further evaluation of the sutureless screw-in electrode for cardiac pacing. J. Thoracic Cardiovasc. Surg., 77:858, 1977.

23. Lawrie, C.M., Seale, J.P., Morris, G.C., et al.: Results of epicardial pacing by the left subcostal approach. Ann. Thorac. Surg., 28:561, 1979.

24. Holmes, D.R., Maloney, J.D. and Feldt, R.H.: The use of the percutaneous subclavian technique for permanent cardiac pacing in childhood. Mayo Clin. Proc., 55:579, 1980.

25. Furman, S, and Young, D.: Cardiac pacing in children and adolescents. Am. J. Cardiol., 39:550, 1977.

26. Karpawich, P.P., Gillette, P.C., Garson, A., Jr., et al.: Congenital complete atrioventricular block: Clinical and electrophysiologic predictors of need for pacemaker insertion. Am. J. Cardiol., 48:1098, 1981.

27. Young, D.: Permanent pacemaker implantation in children: Current status and future considerations. PACE, 4:61, 1981. 
This document is a scanned copy of a printed document. No warranty is given about the accuracy of the copy. Users should refer to the original published version of the material. 